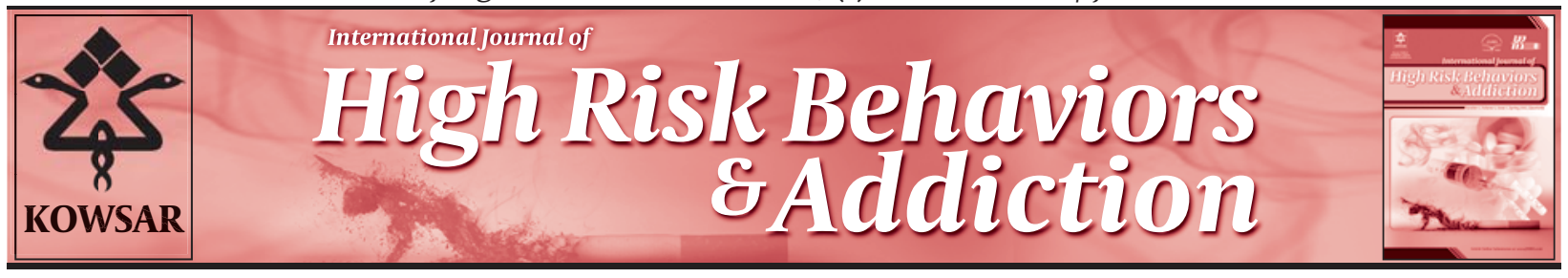

\title{
Methamphetamine Dependency
}

\section{Kobra Lashkaripour ${ }^{1^{*}}$, Elham Torbati ${ }^{2}$}

${ }^{1}$ Department of Psychiatric \& Psychology, Baharan Psychiatric Hospital, Zahedan University of Medical Sciences, Zahedan, IR Iran

${ }^{2}$ Kowsar Corporation

\begin{tabular}{l}
\hline A R T I C L E I N F O \\
\hline Article type: \\
Editorial \\
\hline Article history: \\
Received: 12 Mar 2012 \\
Revised: 25 March 2012 \\
Accepted: 05 Apr 2012 \\
\hline Keywords: \\
Stimulants \\
Methamphetamine \\
Dependency \\
\hline
\end{tabular}

Implication for health policy/practice/research/medical education:

The prevalence of Methamphetamine use and related disorders increased. There are currently no pharmacological treatments for symptoms of Methamphetamine related disorders, because our knowledge about the cellular and molecular mechanisms of Methamphetamine induce psychosis and dependency is limited.

- Please cite this paper as:

Please cite this paper as:

Lashkaripour K, Torbati E. Methamphetamine Dependency. Int J High Risk Behav Addict. 2011;1(1):7-8. DOI: 10.5812/ijhrba.5336

Copyright $\odot 2012$ Kowsar Corp. All rights reserved.

Methamphetamine use and dependency is a serious public health problem with implications across multiple areas from societal impact to burden on psychiatric and medical resources (1). Different areas such as East and Southeast Asia, Australia, Middle West and Western areas of United States and some regions of Great Britain are suffering from Methamphetamine use and related problems (2). An estimated $8 \%$ of admissions to substance abuse treatment programs are associated to stimulants with Methamphetamine misuse (1). The comparison of demographic characteristics and variety of substances in Methadone maintenance clinic of Baharan Psychiatry Hospital in Zahrdan , Iran in 2009-2011, has reported an increasing proceeding of methamphetamine use from $6 \%$ to about $20 \%$ (3). The Administrator of Health and Social anti-drug campaign declared that the substance related psychotic symptoms are noticeable among Methamphetamine users, it has also been reported that $50 \%$ of patients of psychiatric wards consist of Methamphetamine users psychosis patients, which would bring a number of harmful demerits to this the wards (4).

* Corresponding author: Lashkaripour Kobra. Department of Psychiatric \& Psychology, Baharan Psychiatric Hospital, Zahedan University of Medical Sciences, Zahedan, IR Iran. Tel: +98-4514518353. Fax: +98-5414518352. E-mail: dr_lashkaripour@yahoo.com

DOI:10.5812/ijhrba.5336

Copyright $\odot 2012$ Kowsar Corp. All rights reserved.
Methamphetamine is a potent form of amphetamine, administrated through different routes such as: inhalation, smoking, intravenous injection and orally $(2,5)$. The primary effect of Methamphetamines is at the point of the catecholamine release (specially Dopamine), from the presynaptic cells, these effects are stronger among ventral tegmental Dopaminergic neurons connected to the cerebral cortex and limbic system, the activation of this reward pathway may probably lead to amphetamine dependency (5). Craving is the principal cause of drug abuse; Ekhtiari et al. reported that Methamphetamine is a common stimulant substance in Iran, which produce high level of cravings (6). Short term effects of methamphetamine such as initial rush, increased level of energy, appetite and general sense of well-being, would last 6-8 hours. Methamphetamine increases the sex desires and enhances the sexual experience, which is directly related to high risk behaviors including multiple sexual partnership, pregnancy, infectious diseases such as hepatitis and syphilis (7). Restlessness, insomnia, hyperthermia and probably seizures are the side effects of Methamphetamine (2). Addiction, mood disturbance, paranoia, agitation, psychosis, cognitive impairments, poisoning and death are the long-term effects of Methamphetamine $(2,8,9)$. In the past few years, the rate of drug poisoning has been increased among the youngsters (10). Methamphetamine abstinence after a long term consumption 
leads to withdrawal syndrome such as; dysphoric mood, weakness and lethargy, anxiety, nightmare, insomnia, sweating, tension headache and abdominal cramps (6, 11). The withdrawal syndrome will be peaked within 2-4 days and will eliminate after a week and depression associated with suicidal ideation and attempts are the most important symptoms of abstinence (5). The efficiency of pharmacological intervention for treatment of Methamphetamine related disorders is not clear yet $(2,12)$. Different drugs such as sertraline, bupropion, mirtazapine, Modafinil, Dextroamphetamine, Ondansetron, Risperidone, Aripiprazole, Baclofen, Gabapentin and Nalterxon as a treatment of methamphetamine-related disorders were examined, it has been reported that Aripiperazol is the most common drug used $(1,12)$.

Maintenance therapy for Methamphetamine dependency has been suggested, due to increased rate of methamphetamine dependency, low effectiveness of methamphetamine related drug therapy and the good effects of methadone and buprenorphine maintenance therapy in treatment of opioid dependency. Preliminary studies have shown that Dexamphetamine maintenance therapy increases patients' retention in treatment program and decrease methamphetamine consumption (2).

Consistent with low effectiveness of pharmacological interventions and risky behaviors which increase the risk of Human immunodeficiency virus (HIV) and hepatitis transmission among Methamphetamine abusers, it is expected that further investigations related to Methamphetamine dependency and appropriate treatment approaches for more effective treatment would increase the retention of patients by providing therapeutic protocols, however we should consider that Psychotherapy despite the high relapse rate, is still the main treatment. Further surveys with the use of combination models, will provide beneficial and useful treatments to patients with methamphetamine addiction.

\section{Acknowledgments}

The author would like to thank kind co-operation of Miss. Zahra Heidari and Dr. Bakhshani

\section{Financial Disclosure}

None declared.

\section{References}

1. Brackins T, Brahm NC, Kissack JC. Treatments for methamphetamine abuse: a literature review for the clinician. J Pharm Pract. 2011;24(6):541-50.

2. Elkashef A, Vocci F, Hanson G, White J, Wickes W, Tiihonen J. Pharmacotherapy of methamphetamine addiction: an update. Subst Abus. 2008;29(3):31-49.

3. Lashkaripou K, Yusefi M, Ghasemi S, Zabihi R T. The comparison of demographic characteristics and variety of substances in Methadone maintenance clinic of Baharan Psychiatry Hospital in 2009-2010. Abstract book of Fifth Addiction congress in Zahedan. 2012:124.

4. Mehr A. [50\% beds occupied by psychiatric drug useres]. 2012 [updated 2012; cited]; Available from: http:/www.hamyar.rozblog.com/post/84.

5. Sadock BJ, Kaplan HI, Sadock VA. Kaplan \& Sadock's Synopsis of Psychiatry: Behavioral Sciences/Clinical Psychiatry. .Lippincott Williams \& Wilkins; 2007.

6. Ekhtiari H, Alam-Mehrjerdi Z, Hassani-Abharian P, Nouri M, Farnam R, Mokri A. [Examination and Evaluation of Craving-Inductive Verbal Cues among Persian-Speaking Methamphetamine Abusers]. Adv Cogn Sci. 2010;12(2(46)):69-82.

7. Vaziri S, Lotfi Kashani F. [Effects of Methamphetamine and Narcotics On The Increase Of Libido And Reckless Sexual Behavior]. Andisheh va Raftar. 2010;4(15):81-91.

8. Chen $\mathrm{H}, \mathrm{Wu}$ J, Zhang J, Hashimoto K. Recent topics on pharmacotherapy for amphetamine-type stimulants abuse and dependence. Curr Drug Abuse Rev. 2010;3(4):222-38.

9. Simon SL, Domier C, Carnell J, Brethen P, Rawson R, Ling W. Cognitive impairment in individuals currently using methamphetamine. Am J Addict. 2000;9(3):222-31.

10. Izadi-Mood N, Tavahen N, Masoumi GR, Gheshlaghi F, Dana Siadat Z, Setareh M, et al. [Demographic Factors, Duration of Hospitalization, Costs of Hospitalization, and Cause of Death in Patients Intoxicated with Amphetamines and Opioids].J Isfahan Med Sch. 2011;29(146):890-900.

11. Newton TF, Kalechstein AD, Duran S, Vansluis N, Ling W. Methamphetamine abstinence syndrome: preliminary findings. Am JAddict. 2004;13(3):248-55.

12. Karila L, Weinstein A, Aubin HJ, Benyamina A, Reynaud M, Batki SL. Pharmacological approaches to methamphetamine dependence: a focused review. Br J Clin Pharmacol. 2010;69(6):578-92. 